\title{
Crônica de uma ineficiência anunciada? Desempenho e déficit institucional do regime de mudanças climáticas na ONU
}

\author{
Chronicle of an announced inefficiency? \\ Performance and institutional deficit climate change regime at the UN
}

\author{
Diego de Freitas Rodrigues* \\ Doutorando em Ciência Política, \\ Programa de Pós-Graduação em Ciência Política, \\ Universidade Federal de São Carlos - UFSCar, \\ São Carlos, SP, Brasil \\ e-mail: diegofreitas@gmail.com \\ *autor correspondente
}

\section{Andrea Quirino Steiner}

Universidade Federal de Pernambuco,

UFPE, Recife, PE, Brasil

e-mail: ecodea@gmail.com
RESUMo Repousa o regime internacional de mudanças climáticas em uma ineficácia derivada de seu desenho institucional? Para responder essa pergunta, objetiva-se no trabalho transitar e absorver conceitos e constructos teóricos da Ciência Política e das Relações Internacionais com o fim de explicar o desempenho institucional do regime internacional de mudanças climáticas no arranjo institucional das Nações Unidas. Um instrumento conceitual utilizado na teoria política contemporânea e com inferência propositiva interessante para a explicação da aderência do regime de mudanças climáticas no arranjo institucional onusiano é o de accountability. Esse quadro aparentemente indispõe uma transposição conceitual. Mas, acreditamos, apenas aparentemente. Ele é salutar no sentido de observar que responsividade, inferida institucionalmente ante um regime internacional, traz em seu ensejo uma dupla contingência de parâmetros: a decisividade e a resolutividade no trato de um regime. No quadro institucional onusiano, embora inexista a relação principal-agent,é possível visualizar a decisividade em sua configuração institucional no âmbito de sua competência em disseminar entre seus membros um regime (como o ambiental), restringindo a aplicação desse regime às instâncias decisórias da instituição. Quanto ao segundo parâmetro se caracterizaria pela competência de manutenção do regime. Nesse aspecto, a quantidade de atores com poderes de veto influencia diretamente na resolução dessa questão. Nesse sentido, as implicações políticas das mudanças climáticas no desenho institucional da ONU destacam déficits institucionais ancorados na dupla contingência de decisividade e resolutividade na sustentação de regimes ambientais internacionais e nas implicações político-institucionais das mudanças climáticas.

PalaVras-Chave ONU; Desenho institucional; Desempenho institucional; Mudanças climáticas.

ABSTRACT Rest the international regime for climate change in inefficiency derived from its institutional design? To answer this question, we report on work carried over and absorb concepts and theoretical constructs of Political Science and International Relations in order to explain the institutional performance of the 
international climate change in the institutional arrangement of the United Nations. A conceptual tool used in political theory and contemporary practice $\neg$ inference with propositional interesting to explain the adhesion of the regime change in the institutional arrangement onusian is accountability. This picture apparently antagonized a conceptual transposition. However, we believe, only apparently. It is salutary to note that responsiveness, inferred institutionally before an international regime, brings in its opportunity to double contingency of parameters: the decisiveness and resoluteness in dealing with a regime. Within the institutional framework onusian, although not exist a principal-agent relationship, it is pos $\neg$ view the decisiveness in its institutional setting within its competence to disseminate among its members a system (like environmental), restricting the application of that system to decision-makers the institution. The second parameter is characterized by the responsibility of maintaining the system. In this respect, the number of actors with veto powers directly influence the resolution of this issue. In this sense, the policy implications of climate change in the institutional design of the UN stand anchored institutional deficits in the double contingency of decisiveness and resoluteness in support of international environmental regimes and politicalinstitutional implications of climate change.

KEYWORDS UN; Institutional design; Institutional performance; Climate change.

\section{Introdução}

O mediador "natural" no enfrentamento das mudanças climáticas é a Organização das Nações Unidas (ONU), que possui dentro de sua estrutura duas organizações responsáveis pelo tema: o Secretariado da Convenção-Quadro das Nações Unidas sobre Mudança do Clima e o Painel Intergovernamental sobre Mudanças Climáticas, mais conhecido pela sua sigla inglesa, IPCC. A ONU também sustenta dois grandes regimes cujo tema central são as mudanças climáticas: a Convenção-Quadro das Nações Unidas sobre Mudança do Clima (UFCCC) e o resultante Protocolo de Quioto.

Entretanto, o funcionamento destas instituições e a implementação destes regimes enfrenta uma série de entraves que direta ou indiretamente, estão ligadas à própria ONU. Tais entraves serão o foco do presente trabalho, que tem por objetivo principal analisar déficits relacionados a estes organismo em face do problema das mudancas climáticas. O trabalho iniciará com um breve histórico do tema dentro da ONU e sua crescente visibilidade no âmbito político internacional; passará para um resumo das implicações políticas do problema e alguns dos seus desdobramentos teóricos; dará continuidade analisando os principais entraves à mitigação dos seus

impactos e sua resolução de forma geral, apresentando várias possibilidades explicativas; e concluirá com alguns comentários adicionais.

\section{As Mudanças Climáticas Dentro da ONU}

O início da década de 1990 representou um rearranjo histórico nas temáticas da agenda internacional, podendo se usar dois eventos como pontos exemplares: a Guerra do Golfo (1991), "inaugurando" o unilateralismo estadunidense, e a Conferência das Nações Unidas sobre Meio Ambiente e Desenvolvimento, em 1992, no Rio de Janeiro, ou Eco-92. Assim, a reconfiguração dessa agenda se viu em necessidade de readequação, tanto no âmbito da pesquisa quanto no de formulação de políticas. Afinal, o cenário pós-Guerra Fria exigia novas percepções das relações internacionais, tais como o entendimento da globalização nos seus diversos aspectos (econômico, financeiro e cultural) e a importância dos regimes internacionais (meio ambiente, direitos humanos, entre outros). No campo ambiental, este momento foi um verdadeiro esforço para lidar com a "[...] emergência de uma ordem ecológica internacional de características próprias." (Villa, 2006: 07); e o 
caminho para solucionar os novos problemas que surgiam passava pela criação e institucionalização de regimes internacionais de meio ambiente.

O estudo das mudanças climáticas já vinha ganhando peso dentro da comunidade científica desde o início da década de 1980 e, como resposta aos dados levantados pelos acadêmicos nesta área, o Programa das Nações Unidas para o Meio Ambiente (PNUMA) criou, em 1988, o Painel Intergovernamental sobre Mudanças Climáticas, mais conhecido pela sigla inglesa IPCC. O IPCC é de natureza científica, porém não realiza pesquisas: reúne centenas de cientistas de todo o mundo que avaliam grandes quantidades de dados técnico-científicos ligados às mudanças de clima (IPCC, 2007). Seu primeiro grande relatório, lançado em 1990, deu visibilidade ao problema na arena política internacional e iniciou as discussões que resultariam na UNFCCC, assinado por mais de 150 países durante a Eco-92. Como de praxe, paralelamente à convenção foi criado um secretariado para apoiar

[...] a ação cooperativa dos Estados para combater as mudanças climáticas e seus impactos na humanidade e nos ecossistemas. (UNFCCC, 2008: 12).

O lançamento desta convenção na Eco-92 foi muito importante do ponto de vista estratégico. O tema já tinha acumulado peso político ao passar a integrar as prioridades da ONU, o que em conjunto com o embasamento científico do IPCC deu grande ímpeto à questão, mas o tamanho desta conferência deu um ímpeto inicial importante para o desenvolvimento político do tema. Como mencionado anteriormente, a Eco-92 foi um dos pontos marcantes entre tantas outras transformações dos primeiros anos pós-Guerra Fria, além de ter sido uma das maiores conferências da ONU já realizadas, tanto no próprio tamanho (contou com a presença de representantes de 172 países, 108 no nível de Chefes de Estado) quanto na abrangência dos temas a serem tratados. Também ajudou a popularizar o termo "desenvolvimento sustentável" ao inserir o tema "desenvolvimento" ao debate ambiental.

Entretanto, esse impulso inicial foi perdendo força e os resultados que se esperava não foram vistos imediatamente. Apesar da convenção ter entrado em vigor dois anos mais tarde, seu derivado mais prático, o Protocolo de Quioto, só foi assinado em 1997 e somente posto em vigor mais de dez anos após às discussões inIciais, em 2005. O último relatório do IPCC, lançado em 2007, mostra que o problema está longe de ser resolvido. Afinal, além de ser complexo por si só, possui inúmeras implicações sociais, ambientais, econômicas e políticas, que trazem, inclusive, complicadores ao próprio estudo das mudanças climáticas dentro do sistema político internacional.

\section{Implicações Políticas das Mudanças Climáticas e Desdobramentos Teóricos}

Apesar das muitas controvérsias em torno dos dados científicos existentes, é inegável que as mudanças climáticas representam uma enorme ameaça sócioambiental, com potenciais conseqüências que vão desde a extinção de espécies, até o desaparecimento de países-ilha inteiros (Brown, 2001).Outros impactos, incluem, por exemplo, o aceleramento de processos de desertificação, queda nas taxas de renovação dos lençóis freáticos, maior disseminação de pragas relacionadas e diminuição dos estoques pesqueiros.

É possível prever, também, vários impactos econômicos, tais como perdas nos mercados do turismo, agricultura, sistema imobiliário, entre outros. De fato, estudos apontam que os custos totais e os riscos das mudanças climáticas poderão acarretar perdas anuais da ordem de 5\% do PIB mundial num contínuo insustentável, podendo chegar a mais de $20 \%$ com o acúmulo dos impactos negativos. Contudo, existe a contrapartida desse cenário, onde as medidas tomadas gerarão custos consideravelmente menores (como a redução das emissões de gases com efeito estufa e perda de apenas $1 \%$ do PIB mundial) evitando cenários mais degradantes tanto econômica quanto ambientalmente (Banco Mundial, 2006). Definitivamente, é um cenário de urgência que se agrava e que, politicamente, se traduz numa série de situações delicadas e difíceis de solucionar.

Uma das implicações políticas mais óbvias e simples de exemplificar é a dos refugiados ambientais. Atualmente pode-se citar o caso de Tuvalu, um Estado-ilha com cerca de $26 \mathrm{~km}^{2}$ localizado na Polinésia e que vem, há vários anos, tentando encontrar outro país que receba pelo menos 3.000 dos seus quase 12.000 habitantes: talvez os primeiros refugiados do clima a se auto-caracterizarem como tal. Esta nação, cujas praias estão desaparecendo e cujas terras agriculturáveis estão cada vez mais salinizadas devido ao aumento do nível do mar, possivelmente se tornará inabitável nos próximos 30 anos se as questões climáticas não forem enfrentadas de forma apropriada. O país é membro da ONU desde o ano de 2000, além de fazer parte de duas outras organizações relacionadas que tratam da problemática dos países-ilha1; porém, já tentou firmar acordos com a Austrália e a Nova Zelândia para solucionar, com 
pouco sucesso (Hasenclever, Mayer \& Volker, 2000; Macan-Markar, 2008).

Erradicar problemas como este representa uma mudança tão drástica que mesmo os países que têm real interesse em agir enfrentam uma série de obstáculos extremamente difíceis de transpor. Assim, pelo menos a princípio, gera-se um dilema do prisioneiro no melhor estilo da Tragédia dos Comuns, onde os países deixam de agir acreditando que outros resolverão o problema, um complicador que torna-se ainda pior pela participação mínima dos Estados Unidos no processo. Somando-se a isso a assimetria de poder no cenário internacional, a situação torna-se ainda mais complexa, mesmo porque hoje o Estado não é um único ator importante neste sistema: há também as instituições internacionais, as organizações não-governamentais e os próprios regimes, como a UNFCCC e o Protocolo de Quioto. Ademais, conforme as idéias de Mitchell (2007), a própria estrutura do problema, em sua complexidade, pode influir tanto na maneira como este é percebido e tratado no âmbito internacional, quanto no seu estudo.

Um conceito fundamental, criado posteriormente ao termo multidimensional "regimes internacionais", é o de "governança global".

Aqui os regimes constituem-se em temas específicos enquanto a governança tem um pressuposto mais amplo. O conceito clássico de Krasner (1995: 121) para os regimes internacionais traz que estes incluem "[...] princípios, normas, regras e procedimentos decisórios ao redor dos quais as expectativas dos atores convergem numa dada temática."

Por outro lado, James Rosenau afirmou que a governança teria uma postura de ordem global em que

$[\ldots]$ arranjos [...] prevalecem nas lacunas entre regimes e, o que é talvez mais importante ainda, aos princípios, normas, regras e procedimentos que entram em operação quando dois ou mais regimes se sobrepõem, conflitam, ou requerem outros arranjos que facilitem acomodação entre interesses que competem entre si. (Rosenau apud Castro, 2007: p.08)

É interessante, também, visualizar a questão por meio da ótica da teoria dos regimes, ou seja, baseia-se na idéia de que o cenário internacional não apresenta mecanismos que poderiam ser denominados de suficientemente legítimos, levando a reflexões sobre accountability. Embora seja instrumentalizado na teoria democrática, o conceito de accountability pode ser proveitoso se utilizado no sentido de responsividade adequada a um desenho de uma instituição internacional (ou seja, a ONU e seus organismos relativos às mudanças climáticas). Afinal, estas organizações não têm, em seu quadro, a relação principal-agente característica do conceito clássico de accountability.

\section{Entraves ao Enfrentamento das Mudanças Climáticas}

A seção anterior apresentou algumas das implicações políticas das mudanças climáticas, as quais todas podem trazer problemas ao enfrentamento da questão. Também foi visto que o estudo destes entraves possui várias facetas. Algumas destas serão analisadas aqui, usando como fio condutor o déficit institucional: a estrutura do problema e sua relação com as instituições e regimes criados; accountability, decisividade e resolutividade; aprendizado vs. estagnação dos regimes; e, por fim, a assimetria entre os atores (AYOOB, 1993).

Mitchell (2007) argumenta que o primeiro passo para entender quais aspectos institucionais contribuem para a efetividade de um determinado regime é levar em conta a estrutura do problema em questão, pois acredita que a estrutura do problema pode influenciar na própria criação destas instituições. Ele exemplifica comparando a forma como foi implementada aos atos internacionais referentes à camada de ozônio e o comércio de animais silvestres: além do número de atores que produziam as substâncias destruidoras da camada de ozônio ser bem menor do que a potencial quantidade de pessoas que poderiam exercer algum tipo de atividade que envolvesse o comércio ilegal de organismos silvestres, estas particularidades foram essenciais na definição de como atores não-governamentais se posicionaram no acompanhamento de todas estas questões.

No caso das mudanças climáticas, por sua vez, a erradicação rápida e completa do problema necessita de ações não limitadas aos Estados, além de mudanças em grande escala cujos custos os atores envolvidos ainda não desejam ou não podem pagar. Por exemplo, pensar numa transformação radical da matriz energética de alguns países, passando completamente do petróleo para outros combustíveis mais limpos, seria quase inimaginável nos dias de hoje, apesar de existir cada vez mais tecnologia para tal; uma mudança como esta, dependendo da forma que fosse realizada, poderia afetar incontáveis componentes domésticos e internacionais delicados, desde o sustento de pequenas famílias até os lucros de grandes multinacionais. Neste contexto, a estrutura do problema das mudanças climáticas fez com que as instituições e regimes criados para enfrentá-lo fossem pautados, em grande parte, no seu aspecto mais palpável: o econômico. 
O mercado de créditos de carbono e o Mecanismo de Desenvolvimento Limpo (MDL) são exemplos claros disso. De certa forma, pode-se dizer que estes mecanismos ajudaram a reduzir a complexidade do problema a uma dimensão mais compreensível para os principais atores envolvidos, desacostumados a lidar com as inúmeras interconectividades do mundo natural.

Porém, com o vagar das negociações é possível que as metas propostas (que muitos críticos já achavam baixas) sequer sejam atingidas pelas partes, independente do seu componente econômico "mais simples" de lidar. Ademais, este mecanismo possui flexibilidades conhecidamente contraditórias com outros grandes regimes, notadamente o da biodiversidade, ignorando a necessidade de ações de implementação sinérgicas.

Aqui aparecessem duas possibilidades. A primeira, mais tradicional e otimista, é a de que os regimes promovem o aprendizado, o que pode envolver a inclusão de novas informações técnico-científicas, a evolução de conceitos e idéias e o fortalecimento da relação entre os participantes (Dupledge, 2006). Similarmente, Axelrod (1985) defende que o aprendizado pode até ocorrer em situações do tipo dilema do prisioneiro, onde as partes envolvidas evoluem com o processo, melhorando o nível de cooperação entre si. Nesta linha, alguns autores acreditam num melhor desempenho à partir de um novo regime que poderá ter que ser adotado quando a data limite das primeiras metas do Protocolo de Quioto expirar em 2012 (ver, por exemplo, Clemençon, 2008).

Por outro lado, há autores que sugerem uma "ossificação" dos regimes de mudanças climáticas:

Um regime em ossificação é um que, mesmo recebendo novos dados técnicos ou científicos, não consegue processá-los de forma significativa. (Dupledge, 2006: 37).

Esta autora aponta os seguintes indicadores para que isso aconteça: paralização política (alianças demasiadamente estáticas durante todo o processo), a existência de tópicos "tabu" dentro do tema (neste caso, o que acontecerá após 2012) e itens que "travam" ou mesmo param de ser discutidos e estagnação generalizada (que inclui a recorrência de pontos de atrito antigos e a reutilização de textos já acordados previamente).

Tudo isso nos faz retornar à influência da estrutura do problema, visto que sua complexidade é apontada pela autora citada como um dos principais causadores desta ossificação. Porém, alguns autores, tais como Putnam (1996), afirmam que as instituições também moldam as políticas e influenciam a identidade, o poder e a estratégia dos atores políticos, se adaptando e se transformando ao longo de suas trajetórias. Um aspecto que talvez reflita a influência institucional nos regimes climáticos é sua a natureza primariamente remediadora e pouco centrada na importância do equiíbrio climático global para os seres como um todo, como fica claro no trecho da UNFCCC onde objetiva-se

[...] alcançar [...] a estabilização das concentrações de gases de efeito estufa na atmosfera num nível que impeça uma interferência antrópica perigosa no sistema climático. (UNFCCC, 2008: 21).

A convenção diz ainda que

Tal nível deverá ser alcançado num prazo suficiente que permita aos ecossistemas adaptarem-se naturalmente à mudança do clima, que assegure que a produção de alimentos não seja ameaçada e que permita ao desenvolvimento econômico prosseguir de maneira sustentável. (UNFCCC, 2008: 22).

É possível que, segundo as idéias de Putnam (1996), esta postura se transforme num segundo momento de regimes climáticos, baseado no posicionamento da ONU dentro do contexto sócio-político vigente.

Ainda sobre questões do quadro institucional onusiano, embora inexista a relação principal-agente, é possível visualizar a decisividade em sua configuração na sua competência em disseminar entre seus membros um regime (como o ambiental), restringindo a aplicação desse regime às instâncias decisórias da instituição. Existe também resolutividade, parâmetro que se caracteriza na capacidade de manutenção do regime. Assim, as implicações políticas das mudanças climáticas no desenho institucional da ONU sugerem déficits ancorados na dupla contigência de decisividade e resolutividade, tanto na sustentação de regimes ambientais internacionais, quanto nas próprias implicações político-institucionais do tema.

Adicionalmente, levando em conta a dinâmica agência-estrutura, o regime de mudanças climáticas assenta formulações sobre o tema que conformam-se ao quadro de réplicas com a qual Conferência das Partes (COP) pode munir-se. Os negociadores podem, ou não, divergir na formulação de regras cujo teor seja sobre responsabilidades comuns, mas não existiria um imperativo de desafio a tais regras, o que sugere outro ponto importante: um regime, neste caso o de mudanças climáticas, tem dimensões mais superlativas do que seu instrumental jurídico em conluio a ele, já que incorpora diversos segmentos de atores, bem como suas preferências e escolhas 
Neste ponto pode-se utilizar o conceito de accountability, comumente utilizado na teoria democrática e intrinsecamente ligado às questões de agência-estrutura, decisividade e resolutividade. A definição de Moreno et al. (2003) centra-se na capacidade do principal de remover o poder delegado ao agente, que na política geralmente se traduz em não renovar um mandato. Portanto, não haveria relação de accountability entre instituições formalmente independentes (ou instituições internacionais como a ONU), e a relação entre vários agentes não seria de accountability, mas sim de intercâmbio horizontal. Cox e McCubbins (2001), por sua vez, analisam falhas no processo de accountability devido ao número excessivo de grupos de interesse, o que é comum nos cenários internacionais. Estes autores constroem uma argumentação em cima da questão dos diferentes veto points - quanto mais pontos de veto espalhados pelo sistema, maior a probabilidade das políticas terem orientação privada. E, segundo eles, o próprio desenho institucional influirá no aparecimento ou não deste tipo de mal.

A assimetria entre as partes (de poder, econômica, e de informação) é outro complicador, pois apesar de todos os signatários dos regimes de clima terem, em tese, igual poder de voto e veto, há quem aponte para a formatação do Protocolo de Quioto como uma "institucionalização da clivagem norte-sul" ao classificar os países em grupos (Dupledge, 2006). Aqui poder-se-ia ir além e dizer que, de certa forma, há uma institucionalização das clivagens internas dos países, visto que recursos como o MDL são utilizados, primariamente, por empresas, podendo ou não trazer vantagens sociais e ambientais claras para o restante da população. A assimetria informacional é outro problema. Se, de um lado, tecnologias modernas como a Internet têm permitido a larga participação de ONGs e movimentos sociais para pressionar e influenciar os tomadores de decisão em escala internacional (NGLS, 2003), há uma diferença entre as informações que conseguem se tornar "críveis" no cenário internacional (Keohane e Nye, 1998), o que as vezes pode refletir, também, assimetria econômica e de poder. Por fim, a assimetria econômica também se reflete nas ações dos grupos não-governamentais, onde aqueles com mais recursos financeiros (como as multinacionais) podem custear profissionais para fazer lobbies junto aos delegados das conferências, o que nem sempre é possível a outros grupos da sociedade civil, como as ONGs de pequeno porte, que também precisam enfrentar outros obstáculos como barreiras lingüísticas e dificuldades de se cadastrar em instâncias da ONU como a ECOSOC. Todos estes fatores certamente influenciam os resultados das negociações e a capacidade geral de resolução de problema.

\section{Considerações Finais}

As análises apresentadas neste trabalho mostram a dificuldade em lidar com as mudanças climáticas tanto do ponto de vista político, quanto como objeto de estudo. Por outro lado, esta complexidade também abre um leque de possibilidades muito rico, que na academia pode se traduzir em grandes estudos multi e interdisciplinares. $\mathrm{Na}$ arena política internacional, ações mais sinérgicas e integradas são mais difíceis, porém se atingidas poderiam ajudar a promover maior cooperação entre os países e beneficiariam o planeta como um todo.

Apesar da desaceleração no ritmo e fluidez da implementação da UNFCCC a partir da segunda metade da década de 1990, cabe lembrar que nos últimos anos o tema voltou a acumular ímpeto devido ao conteúdo dos mais recentes relatórios do IPCC e a um documentário produzido pelo ex-vice presidente dos EUA, Al Gore, que juntos receberam o Prêmio Nobel da Paz em 2007. Porém, apesar do mercado de carbono estar funcionando bem, as ações concretas para atacar outras frentes do problema parecem ainda estar estagnadas, como mostra o exemplo supracitado de Tuvalu. Por outro lado, com a aproximação do término do primeiro ciclo do Protocolo de Quioto, logo será necessário abrir novas discussões a respeito, como as iniciadas na última conferência realizada em Bali (COP13), em 2007.

O envio do último relatório do IPCC para a apreciação do Conselho de Segurança é uma indicação de que a comunidade internacional começa a ver o problema com outros olhos e perceber que seu escopo vai além de questões econônicas. Entretanto, ações como esta também podem refletir uma situação de deadlock dos regimes de clima, representando, de certa forma, um pedido de socorro. Tal quadro também não é muito animador pela tendência deste conselho, por meio de sua configuração, em manter o status quo (Castro, 2007). Assim, amplas articulações e coalizões setoriais em temas como das mudanças climáticas podem ser profundamente cerceadas. Espera-se que a comunidade internacional e seus múltiplos atores não esperem a chegada de um ponto irreversível para a abordagem incisiva e completa que o tema merece. 


\section{Referências}

Axelrod, Robert e Keohane, Robert. 1985. Achieving Cooperation Under Anarchy: Strategies and Institutions. World Politics, 38(1): 226-254. http:// dx.doi.org/10.2307/2010357

Ayoob, Mohammed. 1983. Security in the third world: the worm about turn?. International Affairs, 60(1). http://dx.doi.org/10.1017/S0260210500113518

Banco Mundial. Managing Climate Risk: Integrating Adaptation into World Bank Group Operations. 2006. Disponível em: <http://econ.worldbank.org >. Acesso em: 12 fev. 2008

Brown, Lester. Rising Sea Level Forcing Evacuation of Island Country. Earth Policy Institute, 2001. Disponível em: <http://www.earth-policy.org/ Updates/Update2.htm>. Acesso em: 16 fev. 2009

Castro, Thales. 2007. Conselho de Segurança da ONU: unipolaridade, consensos e tendências. Curitiba: Juruá.

Clemençon, Raymond. 2008. The Bali Road Map: A First Step on the Difficult Journey to a Post-Kyoto Protocol Agreement. The Journal of Environment Development, 17: 70. PMid:19552863. http://dx.doi. org/10.1177/1070496508314223

Cox, Gary. W. e Mccubbins, Mathew. David. 2001. The Institutional Determinants of Economic Policy Outcomes. In S. Haggard e M. D. Mccubbins. Presidents, Parliaments and Policy. New York: Cambridge University Press.

Dupledge, Joanna. 2006. The Opposite of Learning: Ossification in the Climate Change Regime. Global Environmental Politics, 1(6).

Hasenclever, Andreas; Mayer, Peter e Rittberger, Volker. 2000. Integrating theories of International Regimes. Review of International Studies, 26: 03-33.
International Panel On Climate Change - IPCC. Aspectos Regionais e Setoriais da Contribuição do Grupo de Trabalho II ao $4^{\circ}$ Relatório de Avaliação "Mudança Climática 2007" do IPCC - International Panel On Climate Change. 2007. Dsiponível em: <http://www. iea.usp.br/iea/online/midiateca/mudglobais/index. html>. Acesso em: 08 abr. 2008.

Keohane, Robert e Nye, Joseph. 1989. Power and Interdependence. $2^{\mathrm{a}}$ ed. Addison Wesley Longman, Inc.

Krasner, Stephen. 1995. International Regimes. Ithaca: Cornell University Press.

MaCan-Markar, Marwaan. 2008. Climate Change: Wanted - Homes For Small Island People. IPS News. Disponível em: <http://www.ipsnews.net/news. asp?idnews $=41848>$. Acesso em: 20 abr. 2009

Moreno, E.; Crisp, B. e Shugart, M. D. 2003. The accountability deficit in Latin América. In S. Mainwaring e W. Chirstopher, (eds.), Democratic accountability in Latin America. Oxford; Nova Iorque: Oxford University Press.

Mitchell, Sara McLaughlin e Hensel, Paul. 2007. International Institutions and Compliance with Agreements. American Journal of Political Science. 51(4): 721-737.

Nations Non-Governmental Liason Service - NGLS. 2003. Intergovernmental Negotiations and Decision Making at the United Nations: The NGLS Guide for NGOs. Genebra: NGLS.

Putnan, Robert. 1996. Comunidade e democracia: a experiência da Itália moderna. Rio de Janeiro: FGV.

Villa, Rafael. 2006. Dossiê Política Internacional: Temas Emergentes. Revista de Sociologia e Política, (26): 07-14. http://dx.doi.org/10.1590/ S0102-69092002000300003 